\title{
Os gêneros do discurso no livro didático de língua inglesa da educação de jovens e adultos
}

\section{Discourse genres in english textboooks in the education of youth and adults}

José Rosamilton de Lima ${ }_{* *}^{*}$ Deny de Souza Gandour

Resumo: Neste trabalho analisa-se o livro didático de Língua Inglesa da Educação de Jovens e Adultos, volume único, da editora Educarte (1999), objetivando verificar se esse material didático atende às necessidades de aprendizagem dos alunos nessa modalidade de ensino. Defende-se que o professor de Língua Inglesa deverá buscar meios para a aplicação de um número variado de gêneros do discurso em sala de aula, porque é uma forma do aprendiz inserir-se nas práticas discursivas e compreender melhor as relações sociais nas quais está envolvido. Conclui-se que o livro analisado é um bom material, pois é composto por uma diversidade de gêneros textuais com temas sociais relacionados com a vida do aluno. Além do mais, os referidos gêneros são extraídos de fontes autênticas e prioriza a leitura, a habilidade mais relevante no ensino de Língua Inglesa na Educação Básica.

Palavras-chave: Gêneros do discurso. Ensino de Língua Inglesa. Livro didático.

Abstract: This work analyses the textbook adopted in the education of youth and adults (EJA) in order to verify whether the material meets students' reading abilities needs. It is expected that the language teacher uses a varied number of discourse genres in classroom to help students take an active role in the discursive practices and develop and understanding of the social relations in which they are involved. The analysis of the textbook suggests that the material is adequate as it presents a significant diversity of discourse genres from authentic sources about themes related to students' lives. The textbook also gives priority to reading, which is the most relevant ability in English language teaching in basic education.

Keywords: Discourse genres. English language teaching. Textbook.

\footnotetext{
José Rosamilton de Lima. Especialista em Língua Inglesa e em Linguística Aplicada. Mestrando em Letras. Universidade do Estado do Rio Grande do Norte - UERN. <rosamiltonlima@ hotmail.com>

*** Deny de Souza Gandour. Mestre em Estudos da Linguagem. Universidade Federal do Rio Grande do Norte - UFRN. Professor adjunto da Universidade do Estado do Rio Grande do Norte -UERN. <denygandour@uern.br>
} 


\section{Introdução}

No Brasil, o ensino de Língua Inglesa (doravante LI) tem sido motivo de discussão nos centros acadêmicos, à luz das contribuições da Linguística Aplicada. É evidente a necessidade de aprendermos uma segunda língua, como, por exemplo, o inglês, por ser um idioma universal. Além do mais, os nossos alunos buscam aprender essa língua para desenvolver atividades no seu dia a dia, como realizar a leitura de livros e revistas, de manuais de eletrodomésticos, para viajar, para lidar com o universo da informática, para entender letras de músicas, para compreender filmes, para apresentar nosso país ao estrangeiro e para ter melhores oportunidades de trabalho.

No entanto, é perceptível a pouca credibilidade dada ao ensino de LI na maioria das escolas públicas brasileiras porque, em algumas regiões de nosso país, essa disciplina está fora da grade curricular e é colocada apenas em uma ou duas séries do Ensino Fundamental, sem caráter de reprovação. Por outro lado, podemos constatar que são várias as dificuldades em torno do ensino de LI, citando-se, entre outras, o número excessivo de alunos por turma, a ausência de material didático, pouquíssimas aulas por semana e o despreparo pedagógico do profissional que leciona essa disciplina, e tal situação se torna ainda mais complicada quando se trata da Educação de Jovens e Adultos (EJA).

Vale ressaltar que as propostas para o ensino de línguas direcionam para a abordagem sociocomunicativa, porém, não é o que ocorre na maioria de nossas escolas, pois as aulas de LI são, na maior parte, voltadas para exercícios descontextualizados, explorando apenas os conteúdos gramaticais, fato este que dificulta bastante a permanência do aluno da EJA na escola por causar desmotivação na aprendizagem dessa disciplina.

Assim, na tentativa de proporcionar mais qualidade para a Educação Básica e, consequentemente, para o ensino de LI, surge a abordagem dos PCNs (BRASIL, 1998), que apresentam como temas centrais: a cidadania, a consciência crítica em relação à linguagem, os aspectos sociopolíticos da aprendizagem de Língua Estrangeira (LE), articulando-se com os temas transversais que estão sustentados por dois pilares que regem o processo ensino-aprendizagem de línguas: uma visão teórica da linguagem e o processo de aprendizagem entendido como sociointeracional.

No intuito de auxiliar o aluno na aprendizagem, o livro didático (LD) é um manual elaborado com o objetivo de proporcionar mais infor- 
mações para os alunos através de conteúdos essenciais para a sua formação intelectual. No tocante à EJA, a nova Lei de Diretrizes e Bases (LDB) estabeleceu a oferta de educação regular, com características e modalidades adequadas às necessidades e às disponibilidades do aluno.

Para que se tenha avanço no ensino dessa modalidade, geralmente é disponibilizado livro didático para todas as disciplinas. Devemos considerar as características e interesses dos jovens e adultos, incentivando-os a permanecerem na escola, e um dos fatores principais, dentre tantos outros que compõem essa modalidade de ensino, é a qualidade do LD, pois tal suporte deve atender às expectativas de seus usuários, demonstrando sua verdadeira função em sala de aula.

Face ao exposto, objetivamos analisar o material didático direcionado aos alunos da EJA, buscando verificar se ele atende as suas necessidades de aprendizagem. Nesse sentido, verificamos se os gêneros do discurso oferecidos no livro didático são favoráveis à leitura, proporcionando um maior envolvimento do aluno na prática dessa habilidade, com assuntos do seu interesse, no intuito de estimular sua motivação para o processo de ensino-aprendizagem de LI.

Nessa perspectiva, os PCNs (BRASIL, 1998) destacam a importância da leitura na escola, defendendo que essa habilidade tem uma função primordial, pois aprender a ler em outro idioma pode colaborar no empenho do aluno como leitor em sua própria língua. Nesse caso, as estratégias de leituras aprendidas em inglês podem ser transferidas para a leitura em português e vice-versa, tornando o aluno melhor leitor em ambas as línguas.

O material didático escolhido para análise foi o livro didático "Língua Inglesa: Educação de Jovens e Adultos", volume único, destinado ao Ensino Fundamental, das autoras Heloísa Leme G. de Carvalho, Joseandra Décimo Grazziottin e Luciane Cristine B. Zigmund, publicado pela Editora Educarte em 1999. O referido livro é utilizado em muitas das escolas públicas da rede estadual de ensino.

O corpus escolhido se deve ao fato de ser um manual lançado recentemente e que deverá estar coerente com as inovações que surgem no ensino de LI, como a abordagem de ensino constituída nos PCNs de Língua Estrangeira. 
José Rosamilton de Lima; D eny de Souza Gandour

\section{Caracterização do Livro Didático de Língua Inglesa da Educação de Jovens e Adultos}

Como docente da EJA, podemos dizer que geralmente recebemos o material didático sem termos uma oportunidade de escolha, ou seja, sem termos acesso a outros manuais para que possamos realizar uma escolha mais pensada. Contudo, sem que isso ocorra, devemos pelo menos questionar a qualidade do livro didático (LD) de LI. E se fizermos isso, logo percebemos que os conteúdos contidos nestes manuais são postos de forma pronta e acabada e que, na maioria das vezes, o profissional que leciona essa disciplina, por despreparo pedagógico ou então por comodismo, acaba adotando um ensino mecânico, por consequência da condição imposta pelo próprio LD. Isso torna evidente a autoridade do LD, por ser visto, tradicionalmente, pelo senso comum, como um suporte no qual está depositado um saber definido e acabado.

O caráter do livro didático encontra sua legitimidade na crença de que ele é depositário de um saber a ser decifrado, pois supõe-se que o livro didático contenha uma verdade sacramentada a ser transmitida e compartilhada. Verdade já dada que o professor, legitimado e institucionalmente autorizado a manejar o livro didático, deve apenas reproduzir, cabendo ao aluno assimilá-la. (SOUZA, 1999, p. 27).

Sabe-se que o livro didático de Língua Inglesa, nos estabelecimentos públicos de ensino, só é oferecido na Educação de Jovens e Adultos. Esse fato nos leva a questionar a qualidade desse manual didático, uma vez que, ultimamente, os professores e estudiosos de LI estão admitindo a necessidade e a relevância do LD de língua estrangeira tanto quanto das outras disciplinas.

Os livros de LI geralmente costumam estar divididos em níveis básico, intermediário e avançado, sendo que os conteúdos obedecem, dentro das unidades, a uma sequência de apresentação do mais simples para o mais complexo, e as unidades são prerrequisitos das seguintes, por isso a maioria dos livros didáticos de Língua Inglesa inicia o curso com o verbo to be pelo fato de os autores considerarem esse procedimento uma forma pedagogicamente correta, ao passo que, para o aluno, começar o ano letivo com o verbo to be é um motivo de desinteresse pela disciplina de LI, como percebemos na maioria de nossas escolas públicas.

O livro em análise está dividido em 15 unidades, nas quais estão distribuídas temáticas do nosso dia a dia como, por exemplo, a preservação do 
meio ambiente, o turismo aquático, o amor, os fatos do milênio, a educação, a televisão, a nutrição, as drogas, o espaço, as comidas rápidas, a AIDS, a vida da mulher, os problemas sociais, a saúde. Vale ressaltar que todos os temas são voltados para a faixa etária dos leitores a que se destinam, enfocando em média dois conteúdos gramaticais por unidade.

Além do mais, o referido manual didático possui uma boa diversidade de gêneros do discurso, que deverão ser trabalhados em sala de aula. Contém cerca de oito gêneros: tex to informativo, cartum, letra de música, propaganda, quadrinhos, provérbio, piada e charge, sendo predominante o tex to informativo. A partir dessa diversidade textual, o aluno deverá ser capaz de ler, compreender, analisar e interpretar, enriquecendo o seu vocabulário para que possa conhecer e usar a Língua Inglesa como instrumento de acesso a informações e a outras culturas e grupos sociais. Com base nesses textos são exploradas as seguintes partes: glossary, talking points, a bit of grammar, (grammar) exercises e for fun.

Ainda com relação aos gêneros do discurso, constatamos que não é explorada apenas a linguagem verbal, mas também a linguagem não-verbal, como os textos informativos, propagandas, quadrinhos e cartuns, que apresentam gravuras que auxiliam o aluno para a leitura e, consequentemente, a compreensão do texto escrito, porém essas figuras não são coloridas e acabam de certa forma não sendo atrativas para o aluno.

O livro contém aproximadamente 40 textos, que passaram por um processo de didatização, sendo a maioria adaptação feita de textos extraídos de variadas fontes da área da comunicação, que circulam na sociedade, como Time magazine, uma das mais importantes revistas de circulação mundial, e o jornal Discover, de grande circulação em muitos países. Uma das revistas mais utilizadas por alunos brasileiros que desejam estudar LI é a Speak up, e constatamos que esta revista é a que oferece mais textos no referido livro.

As revistas nacionais também contribuíram com textos que foram adaptados da língua portuguesa para a língua inglesa, e entre elas estão a Veja e a Superinteressante, revistas de grande credibilidade para muitos dos leitores brasileiros. Já os jornais dos quais foram extraídos textos são: a Folha de S. Paulo, e o jornal Pampulha. Ainda foram utilizadas outras fontes que não eram jornais nem revistas, como os quadrinhos de Caulos, provérbios retirados do livro In a Word, de Amadeu Marques, um texto informativo extraído do livro Tudo sobre drogas e outro texto informativo em língua portuguesa 
originário do livro Todos temos direitos. Contudo, as quatro músicas presentes no manual, uma propaganda utilizada no exercício de fixação e uma piada em forma de cartum não tiveram suas fontes indicadas.

Vejamos, no quadro abaixo, as principais fontes que contribuíram para a constituição dos textos do livro em análise, a quantidade e os gêneros oferecidos.

\begin{tabular}{|c|c|}
\hline SUPORTES DE COMUNICAÇÂO & QUANT. /GÊNERO DO DISCURSO \\
\hline Discover & $\begin{array}{c}01 \text { texto informativo } \\
01 \text { propaganda }\end{array}$ \\
\hline Folha de S. Paulo & 01 texto informativo \\
\hline Internet & 01 texto informativo \\
\hline Jornal Pampulha & 01 texto informativo \\
\hline Salete Magazine & 02 textos informativos \\
\hline Speak up & $\begin{array}{c}01 \text { textos informativos } \\
01 \text { piada }\end{array}$ \\
\hline Superinteressante & 01 texto informativo \\
\hline Time magazine & $\begin{array}{c}04 \text { textos informativos } \\
01 \text { propaganda }\end{array}$ \\
\hline Veja & $\begin{array}{c}03 \text { textos informativos } \\
01 \text { piada }\end{array}$ \\
\hline
\end{tabular}

No que diz respeito às quatro habilidades linguísticas: reading, writing, listening, speaking, constatamos que a leitura é utilizada em todas as unidades. O livro apresenta a leitura com o propósito de facilitar a compreensão do texto, sendo esta a habilidade que deve ser realmente priorizada no processo de aprendizagem de Língua Inglesa, pois "a leitura é a única habilidade que o aprendiz pode usar em seu próprio meio. É, assim, a única habilidade que o aprendiz pode continuar a usar autonomamente de acordo com as suas necessidades reais". (MOITA LOPES, 1996, p. 131).

Nesta perspectiva, percebe-se, portanto, que a leitura é realmente essencial à aquisição do conhecimento e mais essencial ainda à própria vida do ser humano, sendo produtivo para o aluno um material didático que propor- 
cione a prática de leitura de forma ativa e prazerosa, e não como comumente observamos na maioria de nossas escolas, um ensino de leitura que está mais para afastar o aluno dessa habilidade, por ser uma atividade mecânica, obrigatória e desestimulante.

Com relação à habilidade de writing, a proposta para o curso da EJA enfatiza o desenvolvimento da leitura e da escrita, objetivando a formação de leitores e produtores de textos que saibam encontrar, compreender e produzir informações escritas, tomando por base o processo de construção do conhecimento. Entretanto, as atividades de produção escrita se restringem apenas aos exercícios de interpretação de textos, na qual os alunos deverão expor suas ideias através de traduções de frases, atividade em que é bastante praticada a língua portuguesa, porém a escrita da LI ocorre mais frequentemente nos exercícios do tipo "passe as frases para a forma interrogativa e negativa", tendo como referência frases afirmativas e a partir de frases no imperativo, e também em quesitos como "passe para o inglês". Visto por esse prisma, podemos observar que existem muitos exercícios com perguntas de alternativas de múltiplas escolhas e atividades gramaticais do tipo "preencha as lacunas com as palavras do quadro", bastante comum com a utilização de músicas.

$\mathrm{Na}$ habilidade de listening, o manual mostra algumas atividades que envolvem músicas relacionadas com os temas desenvolvidos nas unidades, com a finalidade de encerrá-las de uma maneira agradável, muitas vezes trabalhadas em exercícios para enriquecer o vocabulário e, em outras, apenas para a diversão, por isso frequentemente fazem parte da seção for fun.

No tocante à habilidade de speaking, não encontramos atividades dessa natureza, pois os famosos diálogos do cotidiano, vistos como uma forma clássica da comunicação verbal, para ser trabalhada a oralidade, não foram expostos neste manual didático.

Como podemos verificar, todos os gêneros do livro em análise apresentam-se como textos didáticos, selecionados e adaptados com o objetivo de direcionar o ensino de LI, extraídos, geralmente, de importantes jornais e revistas do Brasil e do mundo. É relevante ressaltar que a grande maioria dos alunos da escola pública não tem acesso a estes jornais e revistas, mas tem plena consciência da relevância deles para as pessoas, sendo assim, o ensino com os gêneros do discurso é uma forma de incluí-los nessa sociedade, na era da comunicação. 
José Rosamilton de Lima; D eny de Souza Gandour

\section{Análise dos Gêneros do Discurso no Livro Didático de Língua Inglesa da Educação de Jovens e Adultos}

O gênero textual predominante no livro em análise é o do tipo informativo, com o total de 24 textos. Podemos considerar como fator relevante essa presença predominante do texto informativo, pois esse gênero traz o conteúdo relacionado com outras disciplinas. Segundo Almeida Filho (1998), para o ensino de língua estrangeira, os conteúdos de outras matérias são de grande relevância para a aprendizagem do aluno, porque esses textos tratam de assuntos que não são apenas de natureza comunicativa, mas são também linguisticamente apropriados. Além disso, tais conteúdos já são dosados de acordo com a faixa etária do aluno e com os conhecimentos relacionados ao nível em que estes se encontram em língua estrangeira. Com isso, os aprendizes terão menos dificuldades na compreensão dos textos por se tratar de assuntos que já são do conhecimento deles, como também de serem facilitados pelos recursos visuais que os acompanham.

Vejamos três exemplos de textos que trazem temas polêmicos relacionados à realidade brasileira, veiculados frequentemente na mídia, e que, de certa forma, despertam o interesse do educando.
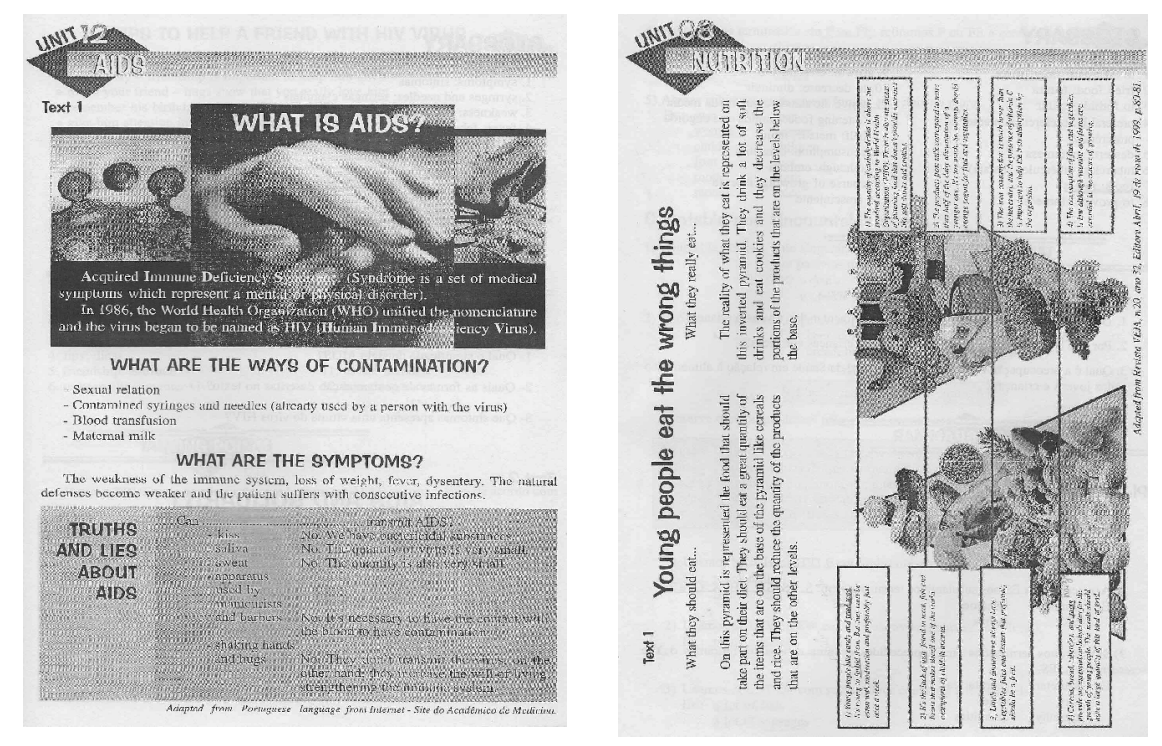


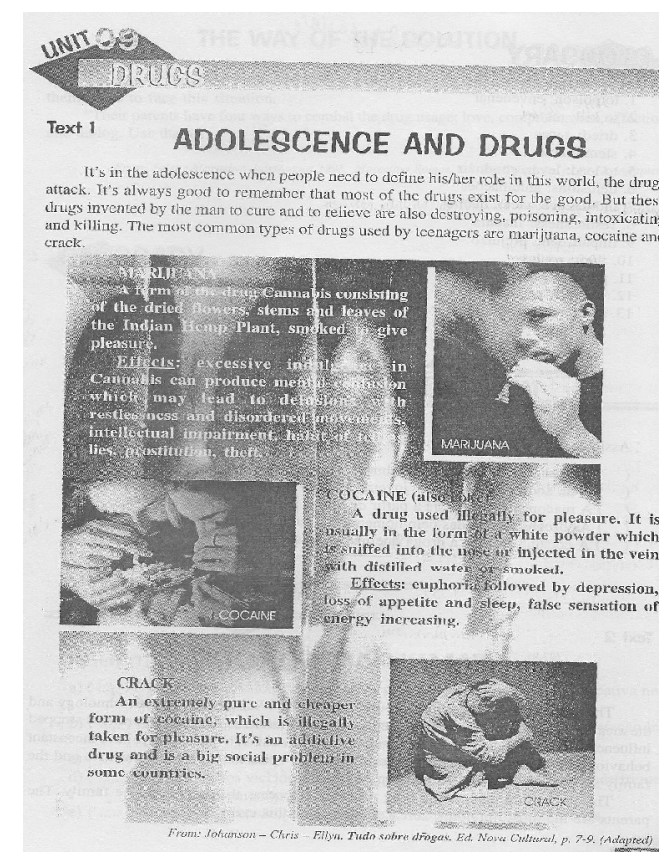

Almeida Filho (1998) ainda acrescenta que esses textos não são apenas meros mostruários de vocabulários e estruturas formais, pois, através de textos dessa natureza se poderia projetar a atenção dos alunos para além dos limites da sala de aula em algo que valesse a pena ser aprendido. Nesta perspectiva, o texto informativo representa o uso autêntico da língua estrangeira, uma vez que os alunos têm acesso a materiais que podem questionar ou não. Além do mais, eles podem assimilar para posteriormente compartilhar com outros, sendo que esses materiais permitem o uso de recursos não linguísticos, tais como fotografias, gravuras, mapas, entre outros.

Diante disto, podemos constatar que o gênero texto informativo é o mais frequente na vida do aluno, visto que no convívio escolar esse gênero é trabalhado em todas as disciplinas, sendo bastante conhecido pelos alunos também no contexto fora da sala de aula, na leitura de jornais, revistas, livros, entre outros. O texto informativo, como o próprio nome já diz, tem como finalidade manter alguém informado sobre determinado assunto, contribuindo, assim, de forma significativa para a vida do aluno, porque o conhecimento repassado pelo texto informativo é de grande relevância para o indivíduo.

Na realidade, o gênero texto informativo não expressa o estilo individual de quem o produz por ser padronizado, pois, segundo Bakhtin (1997), os gêneros que exigem uma forma padronizada oferecem condições menos favoráveis para expressar a individualidade na língua.

Embora os textos informativos expostos no livro didático em análise possibilitem o uso da habilidade de leitura e da escrita, com mais frequência, vale salientar que alguns desses textos são extensos, apresentando um vocabulário difícil, sendo que a lista dada abaixo de cada texto com a tradução 
das palavras mais difíceis para a compreensão do mesmo é insuficiente, se levarmos em consideração as dificuldades dos alunos da EJA.

No livro foram expostas duas propagandas. Sabemos que são características do texto publicitário, ora buscar uma originalidade que estimule as pessoas a fazerem o que é desejado, embelezando uma realidade, ora segue uma direção oposta com bastante artificialismo. A publicidade emprega alguns esquemas básicos para convencer os receptores, como o uso de estereótipos, a substituição de nomes, criação de inimigos, apelo à autoridade e a afirmação e repetição. Vejamos:

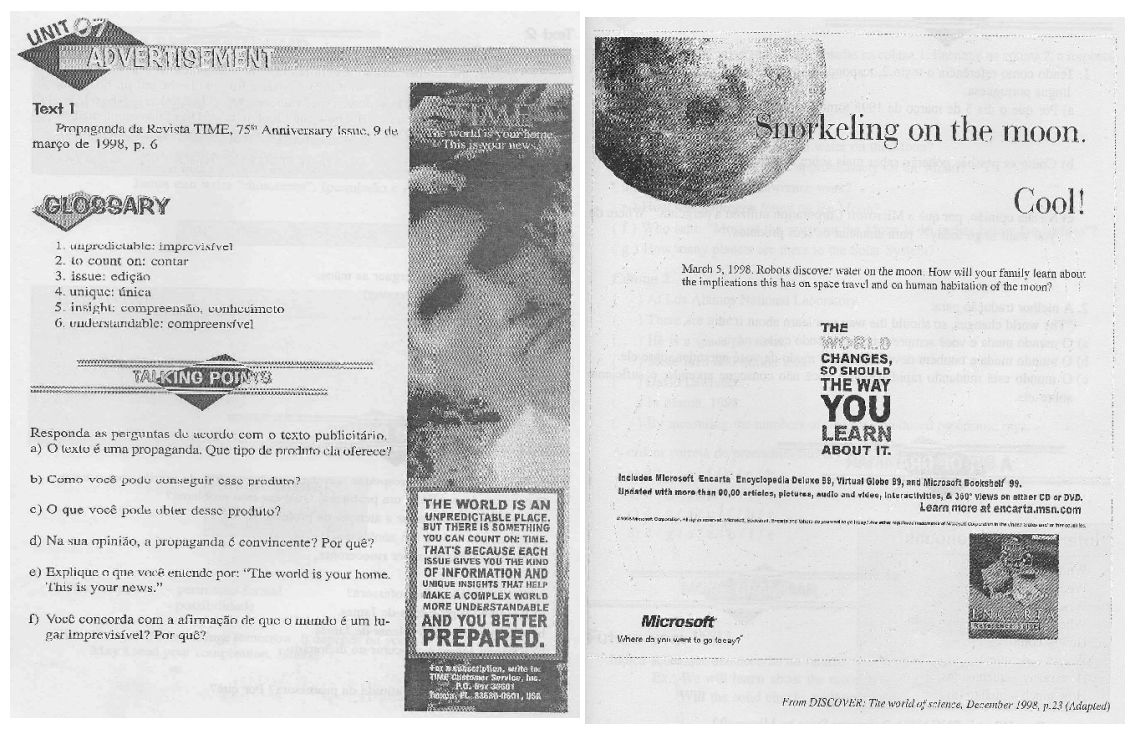

Constatamos um texto interessante para ser trabalhado em sala de aula: trata-se de uma charge: Women's life, na qual uma mulher está servindo comida ao marido, ela trabalha fora de casa, no intuito de adquirir seu próprio dinheiro, só que o marido tenta reprimi-la, criticando o salário que a mesma recebe. Isto provoca uma reação adversa da esposa, que imediatamente revida dizendo que, pelo menos, o seu salário é maior do que se ela estivesse trabalhando em casa. Vejamos a charge: 


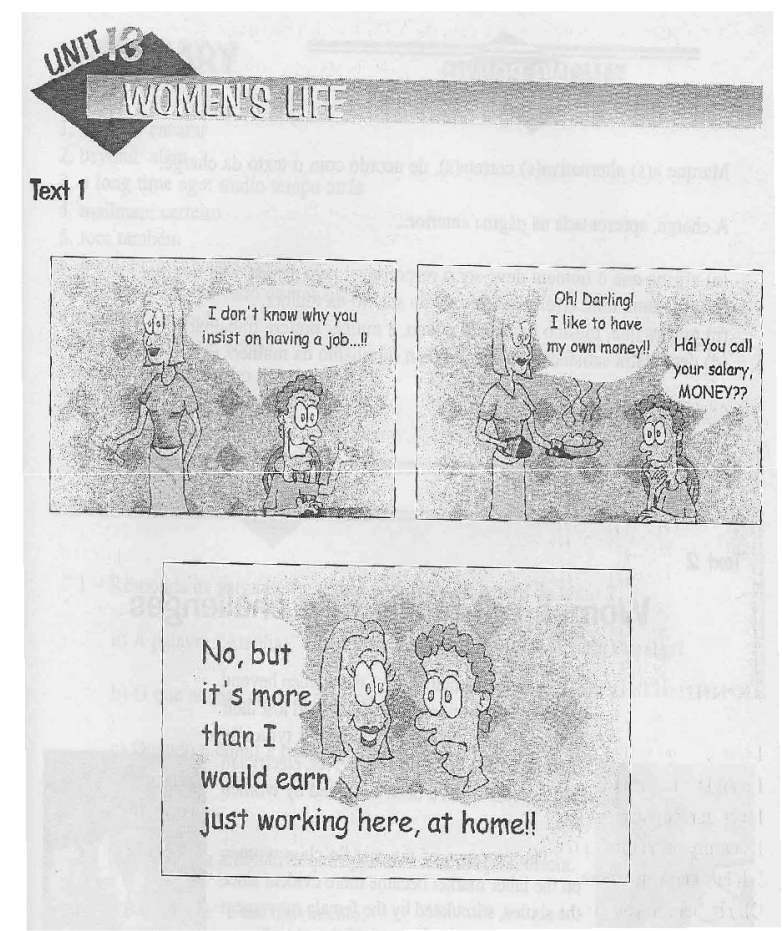

Esse gênero tem muita credibilidade, por ser um estilo de texto diferente do que predomina no livro didático. É um gênero de discurso primário. Segundo Bakhtin (1997), os gêneros primários ou simples são constituídos de diálogo oral, como a linguagem das reuniões sociais, a linguagem familiar, cotidiana, que mantêm uma relação imediata com as situações nos quais são produzidos. A partir desse texto, o professor pode debater a respeito do papel da mulher na sociedade atual.

Observamos também outro texto bastante interessante: World control I remote control, apresentado na seção for fun, é o gênero cartum onde é explicitada uma crítica social de forma bastante humorística, falando a respeito da pretensão dos Estados Unidos em dominar o restante do mundo. Observemos o referido gênero textual: 


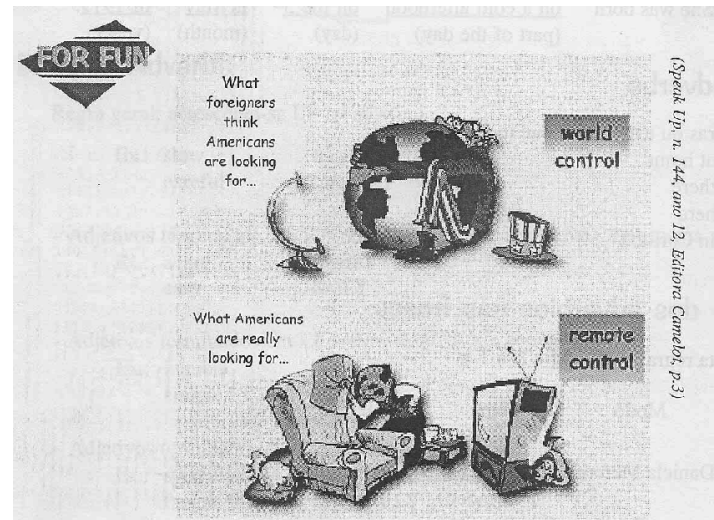

Um tex to nesse estilo, quando trabalhado corretamente, leva o aluno a uma reflexão sobre o assunto, expondo suas ideias e visão crítica. Como se sabe, é próprio desse gênero ser construído fazendo uso da linguagem cômica, um dos recursos linguísticos essenciais para despertar o interesse de muitos alunos pela leitura, como também despertá-los para a reflexão de temáticas de cunho político e social. Desse modo, "a comunicação verbal na vida cotidiana não deixa de dispor de gêneros criativos”. (BAKHTIN, 1997, p. 301).

Os quadrinhos bird's life são um exemplo de outro texto a ser utilizado também na sala de aula e que atrai a atenção dos alunos por não ser extenso, por possuir uma linguagem compreensível e por transmitir uma mensagem de forma bastante agradável. Ou seja, o respectivo cartum expressa o problema do desmatamento através de um pássaro que encontra bastante dificuldade para achar um lugar para construir seu ninho. A história em quadrinhos apresenta os desenhos, os quadros e os balões, onde é inserido o texto verbal. Vejamos os quadrinhos:

Gêneros como a história em quadrinhos, o cartum e a charge são bastante comuns nos periódicos de circulação diária, semanal, mensal, em revistas ou em jornais, com o propósito de passar mensagens através do humor e do entretenimento. Na realidade, gêneros textuais

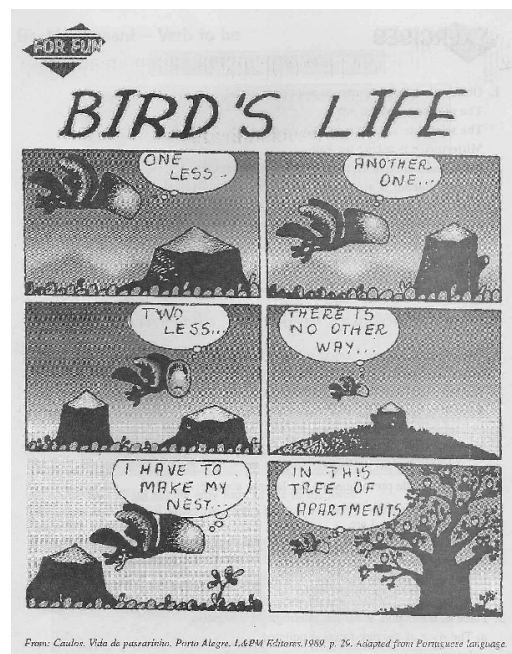


com essas características contêm recursos verbais e não verbais que facilitam a construção de sentidos e, por isso, facilitam aos jovens e adultos, com baixo grau de escolaridade, um maior contato e compreensão da língua estrangeira.

Um bom texto também para ser trabalhado na sala de aula é a joke, do gênero piada, um dito engraçado, que no livro didático em questão vem encerrando a unidade que fala de comida. O texto expõe uma situação irônica de um carioca que deseja "ficar em forma". Por esse motivo, ele faz uma dieta semanal, comparando com um nordestino típico da roça que, por falta de comida não tem uma alimentação regular, é obrigado a fazer dieta todos os dias. Por outro lado, este texto está escrito em língua inglesa e em língua portuguesa, num tom irônico e humorístico, que leva o aprendiz a refletir e compreender melhor as disparidades existentes nos diversos contextos socioeconômicos e culturais de uma dada sociedade. Observemos a piada:

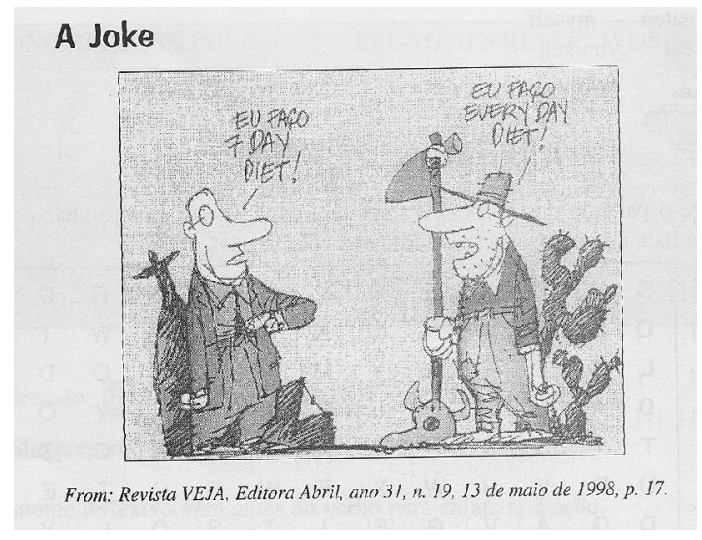

Nesta perspectiva, consideramos relevante a razoável diversidade dos gêneros e a predominância do texto informativo, dispensando a presença dos famosos diálogos didáticos, que são criados artificialmente pelos autores do livro, o que comumente observamos em livros seriados de $5^{\text {a a }} 8^{\mathrm{a}}$ séries. Desta forma, um aspecto positivo é que o livro analisado não possui tal característica, não ocorrendo a presença deste gênero do discurso.

Isto se deve ao fato de o curso da EJA ser constituído por alunos de uma faixa etária mais elevada e apresentar um interesse maior por um gênero do discurso que atenda as suas expectativas, e o texto informativo é o que melhor se adequou a esta característica, porque está relacionado com a vida 
do aluno fora da sala de aula. Neste aspecto, podemos concluir que o livro ora analisado é um bom material. No entanto, o problema maior enfrentado pelos alunos, principalmente os da escola pública, é a carência de um bom vocabulário, talvez decorrente da falta de leitura.

Em síntese, o ensino de LI baseado nos gêneros do discurso voltados para a habilidade de leitura, percebendo os padrões sociais, proporcionará ao aluno, enquanto leitor, melhores condições no desenvolvimento de atividades relacionadas ao ensino-aprendizagem da língua estrangeira.

\section{Considerações Finais}

Tendo em vista as dificuldades de ensinar a LI, como o reduzido número de aulas semanais, a superlotação das turmas, o despreparo pedagógico dos professores, entre outros fatores, ensinar essa disciplina é um grande desafio. E tal realidade também está presente no que se refere à EJA e torna-se até mais delicada por se tratar de um curso que exige aceleração, onde os conteúdos são apresentados de forma bastante resumida, em que os alunos são de faixa etária mais elevada e não vêm de uma permanência frequente na escola, dificultando assim a aprendizagem de LI nesse curso. Nesta perspectiva, os teóricos desta área apontam a habilidade de leitura como a mais relevante dentre as demais.

Na realidade, no convívio escolar, no tocante ao ensino de Língua Inglesa na Educação de Jovens e Adultos, o LD é bastante valorizado, pois, na maioria das vezes, é tido como única base para o repasse de conhecimentos no processo de ensino-aprendizagem. Isso requer bastante atenção quanto à qualidade do LD utilizado e quanto à forma como se trabalha com o mesmo.

Com relação às quatro habilidades linguísticas, constatamos que o livro analisado corresponde aos objetivos propostos para o ensino de LI no sentido de dar prioridade à leitura e trazer atividades relacionadas a essa habilidade em todas as unidades que o constituem. Mas no que diz respeito à escrita e à compreensão de textos orais, as atividades são raras. No tocante à fala, o referido livro não propõe nenhuma atividade relacionada a essa habilidade. Constatamos, também, que cada unidade geralmente se constitui de textos com ilustrações, vocabulário, interpretação do texto, mais propriamente em atividades com questões objetivas, a gramática de forma bastante resumida e exercícios gramaticais que também, em sua grande maioria, apresentam-se 
em questões de múltipla escolha.

Contudo, verificamos que o Livro Didático de Língua Inglesa da Educação de Jovens e Adultos, aqui analisado, apresenta uma maioria de aspectos positivos, como uma boa variedade de textos, que são estratégicos para a aprendizagem do aluno. Por serem adaptações de fontes autênticas de comunicação, com um caráter informativo, essa diversidade textual envolve temática relacionada ao conhecimento de mundo do aluno, baseada em suas faixas etárias e temas sociais como educação, drogas, saúde, meio ambiente, entre outros, que também podem ser integradas a outras disciplinas.

Os gêneros do discurso presentes são: texto informativo, letra de música, cartum, propaganda, quadrinhos, piada, charge e provérbios, e os contextos sociais de uso apresentados são, na maioria, de imprensa, com uma considerável diversidade em relação ao contexto cultural, o que favorece a interdisciplinaridade, e, ainda, alguns textos de contexto publicitário como é o caso da propaganda.

Concluímos, a partir deste trabalho, que mesmo diante de tanta modernidade tecnológica, o livro didático é muito importante no ensino de Língua Inglesa. Cabe, portanto, aos autores, continuar adaptando-o à sociedade moderna, para que seja um suporte fundamental na vida do aluno, dando a oportunidade de treinar o raciocínio, o pensamento crítico e usar as habilidades linguísticas, principalmente a habilidade de leitura. É evidente que os resultados de sua aplicação dependem significativamente da postura docente. Sendo assim, esperamos ter contribuído para uma melhor reflexão sobre o referido material.

\section{Referências}

ALMEIDA FILHO, J. C. P. de. Dimensões comunicativas no ensino de línguas. 2. ed. Campinas, SP: Pontes, 1998.

BAKHTIN, M. Estética da criação verbal. 2. ed. São Paulo: Martins Fontes, 1997.

BRASIL. Parâmetros curriculares nacionais: língua estrangeira: terceiro e quarto ciclos do ensino fundamental. Brasília: MEC/SEF. 1998.

CARVALHO, Heloísa Leme G. de; GRAZZIOTTIN, Joseandra Décimo; ZIGMUND, Luciane Cristine B. Inglês, educação de jovens e adultos: ensino fundamental. Curitiba: Educarte, 1999. 
José Rosamilton de Lima; Deny de Souza Gandour

MOITA LOPES, L. P. da. Oficina de linguística aplicada. Campinas, SP: Mercado de Letras, 1996.

SOUZA, Deusa Maria de. Autoridade, autoria e livro didático. In: CORACINI, Maria José Rodrigues Faria. Interpretação, autoria e legitimação do livro didático: língua materna e língua estrangeira (Org.). Campinas, SP: Pontes, 1999.

Recebido para publicação em 05 jul. 2010.

Aceito para publicação em 24 ago. 2010. 